\title{
Covid-19: should the public wear face masks?
}

\author{
Yes-population benefits are plausible and harms unlikely
}

\author{
Babak Javid principal investigator ${ }^{12}$, Michael P Weekes principal investigator ${ }^{2}{ }^{3}$, Nicholas J Matheson \\ principal investigator $^{2} 34$
} ${ }^{1}$ Tsinghua University School of Medicine, Beijing, China; ${ }^{2}$ Cambridge University Hospitals, Cambridge, UK; ${ }^{3}$ Cambridge Institute of Therapeutic
Immunology and Infectious Disease, Cambridge, UK; ${ }^{4} \mathrm{NHS}$ Blood and Transplant, Cambridge UK

\begin{abstract}
When covid-19 became a global health emergency, there was a visible contrast between the responses of citizens in east Asia and the rest of the world. In east Asia, wearing of masks was ubiquitous, and sometimes mandated by governments. In Europe and North America, concerned citizens were repeatedly told that masks were not recommended for general use.

Now, increasing numbers of agencies and governments, including the Czech Republic and the US Centers for Diseases Control and Prevention ${ }^{1}$ are advocating that the general population wears masks, but others, such as the World Health Organization and Public Health England are not. In a linked article Greenhalgh and colleagues argue in support of the public wearing masks on the basis of the "precautionary principle" (doi:10.1136/bmj.m1435). ${ }^{2}$ So, what is the evidence? And what might be the downsides?
\end{abstract}

\section{Transmission dynamics of SARS-CoV-2}

Maximal viral shedding of SARS-CoV-2 (the cause of covid-19) occurs early in the course of the illness. ${ }^{3}$ Patients may therefore be contagious before they develop symptoms or even know that they are infected. Transmission of SARS-CoV-2 by asymptomatic individuals has been clearly documented, and mathematical models suggest that $40-80 \%$ of transmission events occur from people who are presymptomatic or asymptomatic. ${ }^{45}$ Sneezing and coughing may not be necessary; we know that patients with influenza shed substantial titres of infectious virions during normal breathing. ${ }^{6}$ Together, these data support the idea that seemingly well individuals shedding high titres of SARS-CoV-2 may represent a substantial risk for onward transmission.

Healthcare workers usually wear masks to protect themselves from patients with respiratory infections. At the population level, wearing of masks by infected individuals may be more important, helping to retain contagious droplets, aerosols, and particles that can infect others and contaminate surfaces. Indeed, surgical masks substantially reduce emissions of influenza and (common cold) coronaviruses in exhaled breath, ${ }^{7}$ and in one controlled experiment masks decreased transmission of tuberculosis from humans to guinea pigs by $50 \%{ }^{8}$

Most studies in the real world have focused on the effectiveness of masks in preventing the transmission of influenza. Despite some positive results, several reviews (summarised by Greenhalgh and colleagues ${ }^{2}$ ) as well as a recent meta-analysis ${ }^{9}$ found no significant protection from either face masks or enhanced hand hygiene. Many studies in these reviews were underpowered, and most failed to measure adherence. In one cluster randomised trial, adherence to mask wearing significantly reduced risk of influenza-like illness, but under half of participants wore masks most of the time. ${ }^{13}$

Adherence is likely to be higher during a serious pandemic, and modelling of an influenza pandemic suggested that substantial numbers of cases may still be prevented even if masks are only $20 \%$ effective at reducing transmission. ${ }^{10}$ High quality controlled trials and modelling studies of face mask use during the covid-19 pandemic are urgently required. Nevertheless, Greenhalgh and colleagues state that an "absence of evidence" in this context should not be misinterpreted as "evidence of absence."

In theory, wearing masks could instil a false sense of security and reduce adherence to other respiratory hygiene and social distancing measures. Likewise, contamination may occur when removing masks with imperfect technique. In practice, however, we don't counsel against other non-pharmacological interventions with similar levels of evidence, ${ }^{9}$ just in case they instil a false sense of security. And, as with recent handwashing campaigns, mass education about the safe use and removal of masks would be possible. Importantly, if a mask is contaminated at removal, it has (by definition) already protected the wearer from contagious droplets.

\section{Cloth masks}

One real concern is the shortage of medical grade face masks for frontline healthcare workers, for which evidence of efficacy is more robust. ${ }^{11}$ For the general population, attention has therefore shifted to the use of makeshift or cloth masks. Can 
research findings from studies on medical grade masks be extrapolated to cloth masks? Although good quality evidence is lacking, some data suggest that cloth masks may be only marginally $(15 \%)$ less effective than surgical masks in blocking emission of particles, and fivefold more effective than not wearing masks. ${ }^{12}$ Therefore, cloth masks are likely to be better than wearing no mask at all.

Much remains unknown about the usefulness of population level mask wearing in the context of the covid-19 pandemic. Use of masks in healthcare settings is clearly essential to protect frontline workers, whereas the evidence supporting masks in non-clinical settings is both limited and of variable quality. Nonetheless, unlike stringent isolation and social distancing measures, which have substantial societal and economic costs, mass manufacture and use of cloth masks is cheap and easy, and may even facilitate economic activity.

Greenhalgh and colleagues argue that, given the gravity of the pandemic, indirect evidence of benefit combined with the low risk of harm should outweigh the absence of direct evidence supporting mask wearing by the general public. $^{2}$ We agree. As we prepare to enter a "new normal," wearing a mask in public may become the face of our unified action in the fight against this common threat and reinforce the importance of social distancing measures.

The BMJ has judged that there are no disqualifying financial ties to commercial companies. The authors declare no other interests. The BMJ policy on financial interests is here: https://www.bmj.com/sites/default/files/attachments/resources/ 2016/03/16-current-bmj-education-coi-form.pdf.
Provenance and peer review: Not commissioned, externally peer reviewed.

1 Centers for Disease Control. How to protect yourself. 4 Apr 2020. https://www.cdc.gov/ coronavirus/2019-ncov/prevent-getting-sick/prevention.html?CDC_AA_refVal=https\%3A\% 2F\%2Fwww.cdc.gov\%2Fcoronavirus\%2F2019-ncov\%2Fprepare\%2Fprevention.html.

2 Greenhalgh T, Schmid MB, Czypionka T, Bassler D, Gruer L. Face masks for the public during the covid-19 crisis. BMJ 2020;369:m1435. 10.1136/bmj.m1435

3 Wölfel R, Corman VM, Guggemos W, etal . Virological assessment of hospitalized patients with COVID-2019. Nature 2020. 10.1038/s41586-020-2196-× 32235945

4 Ferretti L, Wymant C, Kendall M, etal . Quantifying SARS-CoV-2 transmission suggests epidemic control with digital contact tracing. Science 2020;eabb6936. 10.1126/science.abb6936. 32234805

5 Li R, Pei S, Chen B, etal . Substantial undocumented infection facilitates the rapid dissemination of novel coronavirus (SARS-CoV2). Science 2020; eabb3221. 10.1126/science.abb3221. 32179701

6 Yan J, Grantham M, Pantelic J, etal. EMIT Consortium. Infectious virus in exhaled breath of symptomatic seasonal influenza cases from a college community. Proc Natl Acad Sci U S A 2018;115:1081-6. 10.1073/pnas.1716561115 29348203

7 Leung NHL, Chu DKW, Shiu EYC, etal . Respiratory virus shedding in exhaled breath and efficacy of face masks. Nat Med 202010.1038/s41591-020-0843-2.

8 Dharmadhikari AS, Mphahlele M, Stoltz A, etal . Surgical face masks worn by patients with multidrug-resistant tuberculosis: impact on infectivity of air on a hospital ward. Am J Respir Crit Care Med 2012;185:1104-9. 10.1164/rccm.201107-11900C 22323300

9 Xiao J, Shiu EYC, Gao H, etal . Nonpharmaceutical measures for pandemic influenza in nonhealthcare settings-personal protective and environmental measures. Emerg Infect Dis 2020;26. 10.3201/eid2605.190994 32027586

10 Tracht SM, Del Valle SY, Hyman JM. Mathematical modeling of the effectiveness of facemasks in reducing the spread of novel influenza A (H1N1). PLoS One 2010;5:e9018. 10.1371/journal.pone.0009018 20161764

11 Offeddu V, Yung CF, Low MSF, Tam CC. Effectiveness of masks and respirators against respiratory infections in healthcare workers: a systematic review and meta-analysis. Clin Infect Dis 2017:65:1934-42. 10.1093/cid/cix681 29140516

12 Davies A, Thompson KA, Giri K, Kafatos G, Walker J, Bennett A. Testing the efficacy of homemade masks: would they protect in an influenza pandemic?Disaster Med Public Health Prep 2013;7:413-8. 10.1017/dmp.2013.43 24229526

13 Macintyre CR, Cauchemez S, Dwyer DE, etal . Face mask use and control of respiratory virus transmission in households. Emerg Infect Dis 2009;15:233-41. 10.3201/eid1502.081166 19193267

Published by the BMJ Publishing Group Limited. For permission to use (where not already granted under a licence) please go to http://group.bmj.com/group/rights-licensing/ permissions 